University of Nebraska - Lincoln

DigitalCommons@University of Nebraska - Lincoln

To Improve the Academy

Professional and Organizational Development Network in Higher Education

1998

Statements of Teaching Philosophy

Gail E. Goodyear

Douglas Allchin

Follow this and additional works at: https://digitalcommons.unl.edu/podimproveacad

Part of the Higher Education Administration Commons

Goodyear, Gail E. and Allchin, Douglas, "Statements of Teaching Philosophy" (1998). To Improve the Academy. 404.

https://digitalcommons.unl.edu/podimproveacad/404

This Article is brought to you for free and open access by the Professional and Organizational Development Network in Higher Education at DigitalCommons@University of Nebraska - Lincoln. It has been accepted for inclusion in To Improve the Academy by an authorized administrator of DigitalCommons@University of Nebraska - Lincoln. 
Goodyear, G. E., \& Allchin, D. (1998). Statements of teaching philosophy. In M. Kaplan (Ed.), To Improve the Academy, Vol. 17 (pp. 103-122). Stillwater, OK: New Forums Press and the Professional and Organizational Deveopment Network in Higher Education. Key Words: self-evaluation, faculty development, portfolios, values.

\section{Statements of Teaching Philosophy}

\section{Gail E. Goodyear}

\section{Douglas Allchin}

University of Texas at El Paso

Well-defined teaching philosophy is essential to creating and maintaining a campus culture supportive of teaching. Presented in this paper are reasons for statements of teaching philosophy as well as descriptions of how the statements are beneficial to students, faculty, and university administrations. Described are ways of creating a statement of teaching philosophy and dimensions that may be included in such statements. This article begins a discussion of roles, composition, and evaluation of statements of teaching philosophy.

Teaching is a scholarly activity when it is purposeful, reflective, documented, and shared in an evaluative forum (Menges \& Weimer, 1996). Articulating an individual teaching philosophy provides the foundation by which to clarify goals, to guide behavior, to seed scholarly dialogue on teaching, and to organize evaluation. Statements of teaching philosophy function both personally and publicly. A professor who writes a teaching philosophy wants to document beliefs, values, and approaches. It may be written to clarify or reflect on practice, to receive feedback from colleagues, or to articulate a view of teaching for administrative decision-making (Murray, 1995). Re- 
gardless of the purpose, the activity demonstrates a deep commitment to teaching and also to growing personally and professionally.

An administration that asks its professors to record formally their teaching philosophies expresses a value for scholarly approaches to teaching and for working toward clearly articulated educational goals. Often professors present their teaching scholarship in a teaching portfolio (Hutchings, 1996; Murray, 1995; Lyons, 1998; O'Neill \& Wright, 1995; Seldin, 1997; Shore, Foster, Knapper, Nadeau, Neill, \& Sim, 1991). A clear statement of teaching philosophy can organize such a portfolio and help determine its content (Lang, 1996; Rodriguez-Farrar, 1997). Thus, statements of teaching philosophy are central to teaching scholarship from several perspectives.

While there now abound many documents on teaching portfolios, or dossiers, there is comparatively little commentary on statements of teaching philosophy, their role, how to compose them, or how to evaluate them as personal statements (see Chism, 1998, for a valuable, brief contribution). In this article, we hope to begin to remedy the dearth. In particular, we will profile how a statement of teaching philosophy functions beyond a mere catalog of teaching responsibilities or strategies. The "why's" of teaching contrast with, but provide an essential foundation for, the "how's" and "what's" of teaching. In addition, we underscore how discussing teaching philosophy is a professional, scholarly activity that contributes to developing a productive culture of teaching - a culture shaped by faculty and supported by faculty development programs.

\section{The Setting}

Our presentation here draws on and summarizes discussions by a group of faculty who developed teaching portfolios through a workshop series. Here, at the University of Texas at El Paso (UTEP), as elsewhere, concerns about evaluating the effectiveness of teaching have grown in recent years. This has primed discussion on teaching itself. In part, through support from a "Model Institutions for Excellence" grant from the National Science Foundation, UTEP has established a Center for Effective Teaching and Learning (CETaL). This center aims to bring faculty together to share their own expertise, to 
characterize effective teaching as an ensemble, and to build a teaching community through professional interaction. Our workshops on teaching portfolios were thus largely initiated by one faculty member (Allchin), who had several years experience in coordinating teaching portfolio development and evaluation within one department. The CETaL professional staff member (Goodyear) provided organizational support and enriched the series with a perspective framed largely by years of dossier (portfolio of teaching, research, and service) preparation and evaluation. Indeed, individual seminars were led by different faculty and/or staff members who each contributed from their own special experiences. Administrators made contributions to the seminars through other faculty or staff members, or in person, if the university political climate allowed. Thus, the specific comments on statements of teaching philosophy that follow exemplify a model format for naturally embedding such documents in institutional practice while ensuring that they reflect the context of a particular institution.

Our workshop series was supplemented by a website that documented its structure, discussions, and outcomes. This was available for those who missed particular sessions, as well as for reference by others. Administrators who were interested in the series, but elected not to stifle discussion with their attendance, were also able to stay informed, and they began to think about how their own work would be shaped by the ongoing discussions. In addition, CETaL acted as a liaison with the Provost, and we profiled CETaL's work during a seminar, designed for department chairs, about supporting teaching scholarship. After the seminar, a number of department chairs visited the website and were able to offer advice to faculty preparing for tenure review and promotion. In addition, we found that, by posting the information publicly, individuals at other institutions were able to benefit from our efforts; several graduate students enrolled elsewhere and, preparing to apply for academic positions, reported that they had found the website useful. We see our campus dialogue becoming part of the national dialogue in this way.

Finally, CETaL supported individual professors with one-on-one consultations. This service was highly valued by faculty who wished privacy for their questions and their professional development. The 
environment created by CETaL was perceived as safe and allowed faculty to explore the largely or somewhat unfamiliar concept of a teaching philosophy. The consultations were performed primarily by one professional staff member; however, this staff member also referred those seeking assistance to others in the community of faculty who would mentor teaching development.

The diverse faculty development strategies employed provided the flexible support necessary for professors with time constraints, various reasons for developing a statement of teaching philosophy or teaching portfolio, and varied degrees of willingness to share their reflections on teaching in a public forum.

\section{Roles of Statements of Teaching Philosophy}

In keeping with the view that teaching is a scholarly activity and that teaching portfolios may serve many audiences and purposes, we invited faculty to discuss why or how teaching philosophy itself is important. Faculty recognized different, overlapping contexts where statements of teaching philosophy might function: for professors, for administrators, and for students.

\section{For Professors}

In preparing a statement of teaching philosophy, professors assess and examine themselves to articulate the goals they wish to achieve in teaching. The process helps the teacher clarify the "why" of teaching as a foundation for the "what" and "how" of teaching, by answering the question: "Why are you teaching?" First, a statement of teaching philosophy (ideally) describes one's identity as a teacher while also providing a focus or theme for teaching activities (Lang, 1996; O'Neil \& Wright, 1997). Second, the statement may define the role of teaching in relation to other professional responsibilities. This can help individuals monitor their commitments and integrate their professional responsibilities of teaching, research, and service. Third, the statement guides behavior by codifying a set of principles by which to act. When someone includes a statement of teaching philosophy in a teaching portfolio, it provides a public rationale, justification, or benchmark for one's actions. It functions simultaneously for self-pro- 
motion and accountability. Finally, when shared with colleagues, the statement can serve as an occasion for professional dialogue, growth, and development.

A clear vision of teaching philosophy provides stability, continuity, and long-term guidance. For example, professors can easily become so overwhelmed by their various responsibilities (i.e., teaching, research, and service) that they may be tempted just to get through each class. A well-defined philosophy can help them remain focused on their teaching goals and to appreciate the personal and professional rewards of teaching. Further, professors may also feel more confident about impending change due to curriculum development or revision when they perceive clearly what they teach and why.

Articulating a statement of teaching philosophy demonstrates the desire to grow as a professional teacher (Lyons, 1998). The professor's commitment to learning leads him or her to clarify and document values and vision at any given moment. Through professional and personal growth, what is expressed in the statement likely evolves and changes throughout one's career. Professors who periodically review and update their statements of teaching philosophy make exemplary role models as life-long learners for students and others with whom they interact.

\section{For Administrators}

University administrators are responsible for guiding the faculty's professional growth and achievement, having an overview of work at the university, and managing a diverse faculty to achieve the university's mission. Yet, professors help shape the university with their own ambitions, values, philosophies, attitudes, and ethical beliefs. Administrators may ask professors to relate their individual teaching ideologies to the university mission statement as a means to have faculty answer the question, "Why are you here at this campus, and why is your presence good for you and good for this institution?" Asking professors to draw this relationship does not reduce or eliminate academic freedom; rather it allows each professor to define his or her individuality in terms of benefit for the university community. 
Administrators may encourage faculty to write statements of teaching philosophy as one means of supporting a culture of teaching. The culture of a faculty that considers teaching philosophy is different from one that does not. Mandating statements of teaching philosophy can reflect an institution's focus on the importance of good teaching. Often, those who write statements of teaching philosophy find themselves moving beyond just trying hard and having good intentions to actively defining themselves as teachers and deliberately pursuing teaching goals. A faculty that actively discusses its teaching pedagogy, methodologies, and strategies develops values, principles, and practices that are shared and enriched by dialogue. Although these interactions create a degree of consensus among faculty, they can also stimulate innovation among some faculty members. Once an institution defines how teachers are to share their teaching philosophies and approaches, administrators can also better support and reward the efforts of the faculty (Seldin, 1993).

Requiring statements of teaching philosophy parallels requiring publication of research and pursuit of a well-considered research program (Hutchings, 1996; Zubizarreta, 1995). Both activities become scholarly when they are shared-and evaluated -in a respected forum (Braskamp \& Ory, 1994). The process of writing statements of teaching philosophy holds the promise of affecting the valuation and role of teaching on a university campus.

A university culture that values teaching requires administrators to evaluate teaching. This is a daunting task that requires one to answer the question, "How does one recognize achievement when strengths and styles differ?" It is through the statement of teaching philosophy that the evaluator discovers the guide: the value of various teaching and scholarly educational activities as understood by the individual professor. Using the statement of teaching philosophy as guide is important given the coupled characteristics of the professorate: academic freedom and responsibility. Commitment to maintaining these characteristics, through an evaluative process that tempts some faculties toward standardization of teaching evaluation, requires flexibility and time of administrators.

Finally, an administration learns about teaching on its campus from reading the statements of its faculty. Such knowledge can be used 
in responding to changing needs and expectations of students and faculty (Seldin, 1993). Hence, the content of the philosophy statements can influence an administration as it pursues its educational mission.

\section{For the Students}

Ideally, professors share their philosophies with their students. They communicate teaching and learning expectations in a variety of written, oral, and nonverbal modes. Overall, students should understand what a professor is doing and why (Cerbin, 1996; Way, 1993). Given this information, students may engage more productively in the learning environment while also knowing how to learn and succeed in the course. Some believe that communicating well to students also increases retention (Braskamp \& Ory, 1994). All professors exhibit implicitly their teaching philosophies and these are evident to students through syllabi, assignments, approaches to teaching and learning, classroom environment, and student-teacher relationships (Zubizarreta, 1995). The goal of sharing a statement of teaching philosophy is to respect and support students by being explicit.

\section{Creating a Statement of Teaching Philosophy}

In our seminars, professors representing all colleges on the campus gathered together to discuss developing teaching portfolios. They began by writing statements of teaching philosophy. The first response fell between the extremes of "I know just what I want to say" to "I haven't considered teaching like this before. Where do I start?" We offered three ways to stimulate reflection and writing. First, we simply described statements of teaching philosophy, emphasizing their focus on values and "why" questions (see "What is a Statement of Teaching Philosophy?" below). This alone prompted some faculty to express their teaching philosophy. Others wanted a process, or protocol, that would lead them stepwise through reflection and expression of their beliefs (see "A Process of Articulating Teaching Philosophy"). The faculty who chose this process discovered it through one-on-one counseling or used it as homework after completing the seminar exercise. Third, some just wanted questions that would elicit frag- 
ments that they could assemble together in an essay. We adopted a standard activity for reflective writing, a "cube" of six questions, as suggested by Axelrod and Cooper (1993) (see "The Teaching Cube"). This exercise, which is in an evolutionary form, proved particularly useful to those who developed their portfolio from information on our website.

\section{What is a Statement of Teaching Philosophy?}

The large question to be answered in a statement of philosophy is: "Why do I teach?" Segments of the larger "why" question include a series of "what" questions:

- What motivates me to learn about this subject?

- What are the opportunities and constraints under which I learn and others learn?

- What do I expect to be the outcomes of my teaching?

- What is the student-teacher relationship I strive to achieve?

- How do I know when I have taught successfully?

- What habits, attitudes, or methods mark my most successful teaching achievements?

- What values do I impart to my students?

- What code of ethics guides me?

- What theme(s) pervade(s) my teaching?

Once professors answer these questions, they can integrate the content to answer the "why" question. Overall, a statement of teaching philosophy should provide a personal portrait of the writer's view of teaching.

The narrative description of one's conception of teaching, as well as one's rationale and justification for how one teaches and why, may be expressed in a variety of ways (Rodriguez-Farrar, 1997; Lyons, 1998; O’Neil \& Wright, 1997; Seldin, 1993; Weber, 1997; Zubizarreta, 1995). The statement of teaching philosophy may be expressed in a statement of beliefs that reflect a value system, a policy statement, a list of objectives and how they are achieved, an essay, or as an art form. Several of our colleagues chose to express their teaching phi- 
losophies in highly creative and individual ways (a poem, a song or a picture with a concept statement); however, acceptance of these forms for purposes other than self-reflection depends on the attitude of the administration. The form does reflect the perspective and the context of teaching. Ideally, the professor's statement of teaching philosophy should communicate the goals of teaching and the corresponding actions of the professor. And because it has to be read by others, it should be insightful, interesting, and lively.

The goals expressed in a statement of teaching philosophy should be definitive enough to meet the departmental and college criteria for academic teaching performance, yet allow enough freedom and spontaneity to maintain an ever-evolving learning environment for both the professor and the student. The statement of teaching philosophy is the expression of desired performance in light of the contextual reality of the professor's university and department. Desired performance refers not only to the professor, but also to the students and how they interact together in a learning environment. A statement of teaching philosophy includes specifics to support the professor's holistic view of his or her teaching.

\section{A Process of Articulating Teaching Philosophy}

Formulation and expression of a teaching philosophy, like any creative exercise, starts with immersion in the idea of teaching. Helpful activities include: watching others teach, listening to what teachers say, and reading about teaching. Further, it is necessary to stretch beyond what one knows and question one's assumptions (Weber, 1997). Why do people teach? Why is learning important? How do teachers decide what and how to teach at a given time? How do others perceive teaching/teachers and why? After answering these questions, the writer should reflect on formal and informal instances of teaching and memorable moments of teaching as touchstones or benchmarks. And, with these in mind, compare them to other teaching approaches and examine how those found memorable support the curriculum taught, the university mission, and oneself. The writer can then consider the wide range of possibilities about how to express a teaching philosophy, as well as what is included and emphasized. Creating and 
presenting a teaching ideology is often enhanced by the contribution of a mentor (Lyons, 1998; Seldin, 1993).

CETaL mentored faculty by encouraging them to learn about how others write and use teaching philosophy statements. Seminar participants were asked to read the philosophy statements of others and examine closely these statements using the questions shown in Figure 1. Further, each reader was asked to identify what he or she responded to favorably and unfavorably in the statements. The insights gained in the preparatory reflection and readings were believed to help in the development of an individualized statement of teaching philosophy.

\section{Figure 1 \\ Questions to Consider About a Statement of Teaching Philosophy}

What words reveal this writer's teaching values?

What is this writer's teaching style?

How does your teaching experience help you understand how and why this writer teaches?

Does the writer gain your confidence and respect? What makes you trust or distrust him or her?

Does the writer ask to be considered in a particular context?

Is what the writer included relevant to the discipline? The department? The university?

Is the writer knowledgeable without coming across as opinionated and dogmatic?

What do you remember the most about this teaching philosophy statement? 


\section{The Teaching Cube}

This exercise requires visualizing teaching as having six facets that can be represented with the following words: Learn, Act, Difference, Values, Setting, and Enjoy. Each of these facets are explored using questions shown in Figure 2. Those who sent their responses into CETaL received a compilation of all responses received.

Faculty responses were identified by discipline so that participants could see the parallels and contrasts they had with others teaching in the same curriculum. Faculty compared these responses to their own and sent in comments to CETaL which, once again, acted as the clearing house.

Those participating in "The Teaching Cube" asked: Can teaching be examined using these questions as the sides of the cube? What other

\section{Figure 2 \\ The Teaching Cube}

Turn over the teaching cube and examine each of its six sides:

(] LEARN: What motivates you to learn about this subject? Why is this mode common? Why would you motivate others similarly?

- ACT: Why do you value certain characteristics in teachers and then express those in your own teaching?

D DIFFERENCE: Why does what you do in your teaching make a difference in the lives of others? Why is it relevant?

$\square$ VALUES: What values do you impart to your students and why?

- SETTING: Why do you develop the learning environment(s) and the relationship with students that you do?

E ENJOY: What are your favorite statements to make about teaching? Why are they favorites?

Note: Use of a cube of questions to write reflectively is described by Axelrod \& Cooper (1993). 
questions might be asked to examine the "why" and "ways" of teaching? Answers to these questions, and the "cube" questions, provided information to be considered for inclusion in the statement of teaching philosophy.

Several faculty continued to send their writing to CETaL and asked for peer review of their teaching philosophy statements. Those who participated in this process used the questions in Figure 1 to give their colleagues feedback. Common recommendations included: set goals about what is to be achieved in the statement; consider the audience who will read the statements and their responsibilities in evaluating teaching; and remember, readers of these statements have much to read and are hurried, so simplify the content by using memorable words and phrases.

\section{Contents of Statements of Teaching Philosophy}

Many faculty starting to write their first statement of teaching philosophy want to know what to include. Since statements of teaching philosophy are personal expressions, there is no required content or set formulation for delivery. Yet, there are dimensions that naturally fit the purpose of such statements. Our faculty group identified the items below during a seminar brainstorming session. Some content in each section came from further correspondence with faculty via e-mail. We added additional information from the literature.

\section{Integration of Responsibilities}

Teaching, research, and service are the traditional responsibilities of a university professor. The demands of these three areas may fragment a professor's activity and thinking into three or more channels, and it is possible for a professor to prioritize one area and relatively ignore the others. Consequently, the concept that the three activities are to meld together and be expressed in teaching may be lost. Ideally, integration of responsibilities and consequent learning benefits are included in a statement of teaching philosophy.

Also, professors may vary widely in how they view themselves supporting the educational mission of the university. While some may easily describe themselves as supporting the university mission, others 
may present themselves as uniquely contributing to the university mission.

\section{Expertise}

Basic to the role of a professor is expertise in one's chosen field. Students perceive effective teachers as ones who have knowledge of the subject matter, as well as the ability to communicate that knowledge clearly and enthusiastically (Bernoff, 1992). However, expression of expertise in a statement of teaching philosophy may vary. The philosophy may describe expertise and modes of teaching and learning in the context of a discipline, department, or university (Braskamp \& Ory, 1994).

\section{Relationships}

The relationships the professor creates and maintains are essential to successful teaching. Student-teacher relationships need to be developed to create the desired teaching and learning environment. Interest in, concern for, and respect for students are essential to effective teaching (Bernoff, 1992). Faculty writing a statement might describe how they create and maintain positive relationships with students. Similarly, the learning environment is enhanced when faculty work effectively with their teaching assistants and with other faculty in the department. Thus, issues of effective collaboration could also be explored in a statement of teaching philosophy. In addition, the breadth of the curriculum experience is expanded as faculty incorporate community service in their course requirements. Faculty can include in their statements comments about how and why they and their students have developed links with the community.

Interestingly, a number of descriptions of effective teachers exist; however, few contain the behaviors, attitudes, and qualities students should also exhibit to contribute to the learning environment (Murray, 1995). A statement of teaching philosophy may describe how the professor and students work together to create an environment conducive to learning. 


\section{Learning Environment}

Although classrooms are assigned, there are many things a professor does to create an environment favorable to learning. Modifications to support learning may be made to the built environment (e.g., rearranging chairs and using technology), to the social environment (e.g., using collaborative or cooperative teaching strategies), to the psychological environment (e.g., defining expectations), or to the physical boundaries of the classrooms (e.g., adding e-mail and out-ofclass meetings to the course structure). These all can be done in a purposeful manner to support a philosophy of teaching and learning.

\section{Values Imparted}

Teaching is a value-laden activity and the forthright professor communicates his or her expectations to students. Often the communication used is a syllabus - a common piece of evidence used in a teaching portfolio (Hutchings, 1996; Lang, 1996). In effective syllabi, a professor delineates expectations of students congruent with his or her teaching philosophy. The content of the syllabus, as well as the course objectives contained therein, reflect the valuation placed on content knowledge, performance, skills, and behavior. Beyond professor preference, emphasis on each of these are dependent on the course content, the curriculum, the university, and the community. Academic freedom allows professors, within the limits of the law, to also impart selected social, political, economic, and cultural views into the learning environment. A statement of teaching philosophy often is a thoughtful presentation of selected and prioritized values.

\section{Methods, Strategies, and Innovation}

There are a myriad of teaching strategies, techniques, and tips. What works for one professor may be the same way he or she was taught, and if that doesn't work, a new way might be developed. Teaching philosophy statements may reflect well-tested approaches as well as new ones. Use caution in valuing only the latest, fashionable approaches to teaching. What is important is that there is a firm foundation behind why, what, and how teaching is done. Some teaching portfolios include discussion of how teaching strategies match 
one's philosophical assumptions about learning and the goals of teaching (Murray, 1995).

\section{Outcome}

Success in achieving teaching goals is measured in a variety of ways. It can mean communicating well to students how to succeed in a course; making a difference in the lives of students; receiving and maintaining accreditation; or meeting expectations of growth and change. The basic assumption of teaching is that students will be different after the interaction. In the statement of teaching philosophy, faculty can express their view of the intended outcomes of teaching. One question to consider is: Beyond facts, what should students gain from courses (e.g., thinking skills, attitudes, values, technical skills, etc.)? Faculty might start with a general description of the most important learning goals and then give some examples from specific courses. If syllabi or exams are included in the portfolio, faculty can refer the reader to the appropriate sections for more detail.

Further, teaching is positively impacted when the administration recognizes and supports scholarly teaching efforts (Braskamp \& Ory, 1994). A professor could describe how his or her teaching has been recognized and rewarded.

\section{Recommendations to Faculty Developers}

The process of expressing a teaching philosophy asks professors to compare their theoretical self with their actual self. We recommend you facilitate the process to allow a personal reflection, a variety of outcomes, as well as creation of that which is required by the university. Currently, each department at the University at Texas at El Paso has its own protocol for faculty review, retention, promotion, and merit pay. Consequently, the recommendations of the faculty developers had to be adapted for each faculty member. The following checklist can guide faculty developers as they work with faculty.

- Build a support network of administrators and institutional leaders of opinion for discussions of teaching based on the strong links 
among statements of teaching philosophy, teaching portfolios, and institutional review of teaching.

- Develop a framework to support faculty discussions of teaching performance, evaluation, and excellence. The administration that allows each department to set criteria of evaluation and reward fosters appreciation for varied modes of learning. At UTEP, a skeletal framework for portfolios was derived from the literature. Because it left much to the discretion of individual faculty members, it fostered creativity and excitement about the possibilities of teaching. Conversely, whenever discussions focused on how to conform to imposed standards of teaching, participants left exhausted.

- Let the faculty drive the teaching discussions by asking a lot of probing questions and supporting a variety of perspectives.

- Emphasize the most important question about teaching: Why? Why do you teach in the ways you do? Until the professor can articulate the "why," he or she has not thought through and internalized the teaching-learning process.

- Let the context of the statement of teaching philosophy determine its content, format, and presentation. A statement of teaching philosophy used only for personal reflection and growth may differ widely from one used to communicate teaching ideals to a review committee.

- Encourage faculty to define themselves, as members of the academic community, in relation to the university mission. For it is this definition of relationship to the community that will support their work and help them survive and flourish in the university.

- Prompt visualization of committing to a teaching philosophy as a means to guide a professor as he or she integrates teaching, research, and service into a rewarding academic life.

This paper is a testimonial to the faculty who wanted to explore teaching philosophies, to use several ways of creating them, and to sharing their work with others. Besides sharing their ideas with The Center for Effective Teaching and Learning (CETaL) in the creation of this paper, many shared their teaching philosophies with their students and asked, "How am I doing?" This communication with 
students was not prompted by CETaL, but was a result of faculty who felt accountability to students was a high priority. These faculty felt that asking students directly about the congruency between the professor's philosophical self and actual teaching was most appropriate. Willingness to take the risk associated with such open communication with students was directly related to the support network faculty created for themselves in their discussions of teaching.

\section{Conclusion}

Statements of teaching philosophy stimulate personal reflection in a process that can yield professional growth and achievement, as faculty examine whether their actions inside and outside the classroom match their beliefs about teaching. Reflecting and articulating beliefs through writing is a powerful process that takes time and commitment. When faculty members are asked to write these statements to guide their teaching, it can open campus-wide discussions that lead to common understanding of teaching expectations, as well as innovative teaching. Overall, the process holds the promise of affecting the valuation and role of teaching on a university campus.

\section{References}

Axelrod, R. B., \& Cooper, C. R. (1993). Reading critically, writing well: A reader and guide (3rd ed.). New York: St. Martin's.

Braskamp, L. A., \& Ory, J. C. (1994). Assessing faculty work: Enhancing individual and institutional performance. San Francisco: Jossey-Bass.

Bernoff, R. A. (1992, March). Effective teaching techniques: A workshop. Paper presented at the National Conference on Successful College Teaching and Administration, Orlando, FL.

Cerbin, W. (1996). Inventing a new genre: The course portfolio at the University of Wisconsin-La Crosse. In P. Hutchings (Ed.), Making teaching community property: A menu for peer collaboration and peer review. Washington, DC: American Association of Higher Education.

Chism, N. V. (1997-98). Developing a philosophy of teaching statement. Essays on Teaching Excellence: Toward The Best in the Academy, 9(3).

Hutchings, P. (Ed.). (1996). Making teaching community property: A menu for peer collaboration and peer review. Washington, DC: American Association of Higher Education. 
Lang, J. M., \& Bain, K. R. (1996). Recasting the teaching portfolio. Evanston, IL: The Searle Center for Teaching Excellence at Northwestern University.

Lyons, N. (Ed.). (1998). With portfolio in hand: Validating the new teacher professionalism. New York: Teachers College Press.

Menges, R. J., \& Weimer, M. (1996). Teaching on solid ground: Using scholarship to improve practice. San Francisco: Jossey-Bass.

Murray, J. P. (1995). Successful faculty development and evaluation: The complete teaching portfolio (ASHE-ERIC Higher Education Report No. 8). Washington, DC: The George Washington University, Graduate School of Education and Human Development.

O'Neil, C., \& Wright, A. (1997). Recording teaching accomplishment: A Dalhousie guide to the teaching dossier. Halifax, Nova Scotia: Dalhousie University.

Rodriguez-Farrar, H. B. (1997). The teaching portfolio: A handbook for faculty, teaching assistants and teaching fellows (2nd ed.). Brown University: Harriet Sheridan Center for Teaching and Learning.

Seldin, P. (1993). Successful use of teaching portfolios. Bolton, MA: Anker.

Shore, B. M., Foster, S. F., Knapper, C. K., Nadeau, G. G., Neill, N., Sim, V., \& Caron, L. (1991). The CAUT guide to the teaching dossier: Its preparation and use. Ottawa, Ontario: Canadian Association of University Teachers.

Way, D. G. (1993). Teaching evaluation handbook. Ithaca, NY: Cornell University Office of Instructional Support.

Weber, J. A. (1997). Preparing the portfolio: A personal view. In P. Seldin (Ed.), The teaching portfolio: A practical guide to improved performance and promotion/tenure decisions (2nd ed.). Bolton, MA: Anker.

Zubizarreta, J. (1995). Using teaching porfolio strategies to improve course instruction. In P. Seldin (Ed.), Improving college teaching. Bolton, MA: Anker.

\section{Contact:}

Gail Goodyear

Center for Effective Teaching and Learning

P.O. Box 68664

El Paso, TX 79968-9991

(915) 747-8794

(915) 747-5654 FAX

goodyear@utep.edu

Gail Goodyear is the Director of the Center for Effective Teaching and Learning at the University of Texas at El Paso. She taught product development, quality control, and systems theory at the California State University, Chico, for 15 years. The teaching strategies she developed there have been shared in national and international forums, and she has received awards for creating supportive learning environments for students. 
Douglas Allchin is a historian and philosopher of biology whose research focuses on how scientists recover from error and resolve their disputes. He also carries his expertise into science education, serving as Associate Editor for Science \& Education and coordinating a national network of teachers interested in the history and nature of science. 